\title{
Physico-chemical regeneration of high silica zeolite $Y$ used to clean-up water polluted with sulfonamide antibiotics
}

I. Braschi ${ }^{1,2^{*}}$, S. Blasioli ${ }^{1}$, E. Buscaroli ${ }^{1}$, D. Montecchio ${ }^{1}$, A. Martucci ${ }^{3}$

${ }^{1}$ Department of Agricultural Sciences, University of Bologna, Bologna 40127, Italy

${ }^{2}$ NanoSiSTeMI Interdisciplinary Centre, Università del Piemonte Orientale A. Avogadro, Alessandria15121, Italy

${ }^{3}$ Department of Physics and Earth Sciences, University of Ferrara, Ferrara 44122, Italy

* corresponding author: ilaria.braschi@unibo.it

\begin{abstract}
High silica zeolite Y has been positively evaluated to clean-up water polluted with sulfonamides, an antibiotic family which is known to be involved in the antibiotic resistance evolution. To define possible strategies for the exhausted zeolite regeneration, the efficacy of some chemico-physical treatments on the zeolite loaded with four different sulfonamides was evaluated. The evolution of photolysis, Fenton-like reaction, thermal treatments, and solvent extractions and the occurrence in the zeolite pores of organic residues eventually entrapped was elucidated by a combined thermogravimetric (TGA-DTA), diffractometric (XRPD), and spectroscopic (FTIR) approach. The chemical processes were not able to remove the organic guest from zeolite pores and a limited transformation on embedded molecules was observed. On the contrary, both thermal treatment and solvent extraction succeeded in the regeneration of the zeolite loaded from deionized and natural fresh water. The recyclability of regenerated zeolite was evaluated over several adsorption/regeneration cycles, due to the treatment efficacy and its stability and ability to regain the structural features of the unloaded material.
\end{abstract}

Keywords: zeolite recyclability, water depollution, sulfa drugs, thermal regeneration, solvent extraction

\section{Introduction}

Adsorption of organic pollutants onto organic or inorganic sorbents is considered one of the most effective technologies for the wastewater treatment (Martucci et al., 2014; Rivera-Utrilla et al., 2013). After adsorption, exhausted materials should be regenerated and reused in order to avoid secondary environmental problems due to the disposal of contaminated materials. The sorbate 
characteristics, the nature of adsorption, and the regeneration costs affect the choice of the regeneration process (Leng and Pinto, 1996; Nahm et al., 2012).

The most common regeneration technique consists in thermal treatments, where adsorbed molecules are volatilized and/or oxidized by heating. Alternatively, the solvent extraction of entrapped molecules is considered another efficient technique. Other methods include photochemical, biological, vacuum, electrical/electrochemical, and supercritical fluid treatments, as well as microwave and ultrasounds.

Although activated carbons are the most widely used sorbents (Cooney, 1999) in wastewater treatment technology, zeolites are considered competitive materials in terms of cheapness, shape selectivity, and adsorption efficacy (Ahmaruzzaman, 2008). These sorbents are characterized by high surface area and excellent adsorption properties and are largely applied for the removal of cations or organic compounds from effluents (Bish and Ming, 2001; Kesraoui-Ouki et al., 1994; Martucci et al., 2012; Navalon et al., 2009: Rossner et al., 2009; Tsai et al., 2006). The capacity to retain different solutes mainly depends on the $\mathrm{SiO}_{2} / \mathrm{Al}_{2} \mathrm{O}_{3}$ ratio that can be modulated in order to preferentially entrap hydrophilic or hydrophobic molecules.

High silica zeolites, namely hydrophobic zeolites with high affinity for organic molecules, have been recently applied for the removal of sulfonamides antibiotics (sulfa drugs) from water in laboratory conditions (Braschi et al., 2010a; Fukahori et al., 2011; Braschi et al., 2013; Blasioli et al., 2014). Sulfonamides are a broad spectrum antibiotic class largely used in human and animal therapy and are known to contribute to the evolution of antibiotic resistance phenomena (van der Ven et al., 1994; van der Ven et al., 1995; Gao et al., 2012). Sulfa drugs are potentially highly mobile in non-acidic soils, thus favoring their accumulation in water bodies due to their anionic nature (pKa value in the range 5.0 - 7.5) and are not completely transformed by activated sludge in wastewater treatment plants (Gao et al., 2012). The occurrence of antibiotics in natural waters is one of the main reason of the spreading of microbial antibiotic resistance which, in its turn, makes the antibiotics less effective (Acar and Rostel, 2001).

A high silica zeolite $\mathrm{Y}\left(\mathrm{SiO}_{2} / \mathrm{Al}_{2} \mathrm{O}_{3}=200\right)$ has been found able to clean-up water polluted with sulfonamides (up to $28 \%$ of zeolite dry weight - DW) with a very favorable kinetics $(<1 \mathrm{~min}$ ) (Braschi et al., 2010a; Braschi et al., 2013; Blasioli et al., 2014). According to these studies, each zeolite cage (ca. $4 \times 10^{20}$ cages $\mathrm{g}^{-1}$ zeolite (Braschi et al., 2010a) is occupied by an antibiotic molecule, on average. In addition, the sulfa drug adsorption in the zeolite porosity has been found not affected by the presence of dissolved organic matter.

Leardini et al. (2014) have recently investigated the thermal regeneration of high silica zeolites loaded with sulfamethoxazole sulfonamide by an in situ high-temperature synchrotron XRPD study. 
The study has been carried out on samples treated at $575{ }^{\circ} \mathrm{C}$ for $2 \mathrm{~h}$ and, in these conditions, the degradation pathway of the embedded antibiotic has been defined. The architecture of treated zeolite was found unmodified, thus allowing the sorbent reuse for water depollution.

Four sulfa drugs were selected for this study because of their different structures as shown in Figure 1: a six membered diazine ring in sulfadiazine - SD - and sulfamethazine - SM; a six membered pyridazine ring in sulfachloropyridazine - SC - and a five membered isoxazole ring in sulfamethoxazole - SMX. Since the thermal treatment efficacy on exhausted zeolite Y can be affected by the chemical structure of embedded molecules, in this study the efficacy of the thermal treatment was reconsidered on zeolite Y loaded with the four sulfa drugs and compared to the performance of solvent extractions. The development of chemical processes as Fenton and Fentonlike for soil, wastewater and manure decontamination (Rivas, 2006; Dec et al, 2007; Riviera-Utrilla et al., 2013;), along with the well-known susceptibility of the sulfonamide moiety to photolytic cleavage (D'Souza and Day, 1968), prompted us to test photolysis and Fenton-like conditions for the regeneration of sulfonamide loaded-zeolite Y. The Fenton-like reaction in the presence of $\mathrm{Fe}^{3+}$ was preferred to Fenton reaction with $\mathrm{Fe}^{2+}$ owing to the ease of $\mathrm{Fe}$ (II) to be oxidized to $\mathrm{Fe}$ (III) during the reagent storage and handling.

The zeolite was loaded with the sulfonamides, chosen for their occurrence in water bodies and soils (Ungemach, 2012; Lindsey et al. 2001), in order to supply exhausted samples to be treated for regeneration purposes. The efficacy of the adopted regeneration techniques, the zeolite characterization before and after treatments, as well as the process evolution, were elucidated through a combined thermogravimetric, diffractometric, and spectroscopic analyses. Once the best regeneration conditions were identified, the treated zeolite $\mathrm{Y}$ was tested over several adsorption/regeneration cycles in both deionized and natural fresh water.

\section{Materials and Methods}

\subsection{Chemicals}

Sulfadiazine (4-amino-2- $N$-pyrimidinyl-benzenesulfonamide, MW $250.3 \mathrm{~g} \mathrm{~mol}^{-1}$; 99\% purity), sulfamethazine (4-amino- $N$-(4,6-dimethyl-2-pyrimidinyl)benzenesulfonamide, MW $278.3 \mathrm{~g} \mathrm{~mol}^{-1}$; $99 \%$ purity), sulfachloropyridazine (4-amino- $N$-(6-chloro-3-pyridazinyl)benzene sulfonamide, MW

$284.7 \mathrm{~g} \mathrm{~mol}{ }^{-1} ; 98 \%$ purity) and sulfamethoxazole (4-amino- $N$-(5-methylisoxazol-3yl)benzenesulfonamide, MW $253.3 \mathrm{~g} \mathrm{~mol}^{-1}$; 99\% purity) were purchased from Sigma-Aldrich Co LLC (USA) in powder form. The chemical structure and the $p K_{a}$ value of the antibiotics are reported in Figure 1. 
Stock solutions of each antibiotic at its maximal solubility were prepared by adding to Milli- ${ }^{\circledR}$ water an amount of sulfonamide exceeding the saturation concentration. Each drug suspension was then sonicated for $15 \mathrm{~min}$ at room temperature (RT) in order to speed up the dissolution process. Undissolved drug particles were then filtered through $0.45 \mu \mathrm{m}$ Durapore ${ }^{\circledR}$ membrane, and the antibiotic concentration of each supernatants evaluated by high performance liquid chromatography (HPLC). The maximal solubility of SD, SM, SC, and SMX was 71.9 $\pm 4.8,138.5 \pm 3.7,176.3 \pm 7.2$, and 203.2 $\pm 2.4 \mu \mathrm{M}$, respectively (Table 1). If needed, Milli- $\mathrm{Q}^{\circledR}$ water diluted solutions were prepared starting from stock solutions.

Y type faujausite zeolite powder with a $200 \mathrm{SiO}_{2} / \mathrm{Al}_{2} \mathrm{O}_{3}(\mathrm{~mol} / \mathrm{mol}$ ) ratio (code HSZ-390HUA) and with pore access window of $7.1 \AA \times 7.0 \AA$ was purchased from Tosoh Corporation (Japan).

\subsection{Zeolite loading from deionized water}

The maximal sulfonamide loading of zeolite was achieved by adding to the zeolite a volume of antibiotic aqueous solution at its maximal solubility which contained a drug amount slightly exceedingly the loadable amount. The maximal adsorption capacity of zeolite Y towards SD, SM, SC, or SMX has been previously measured (ca. 15\%, 21\%, 26\%, or 24\% zeolite DW, respectively (Braschi et al., 2010a; Blasioli et al., 2014). In the present study, $850 \mathrm{~mL}$ of aqueous SD solution at the maximal solubility (Table 1) were added to $100 \mathrm{mg}$ of the zeolite, whereas $550 \mathrm{~mL}$ for SM or $\mathrm{SC}$, and $500 \mathrm{~mL}$ for SMX were used. In accordance to the very favorable adsorption kinetics of sulfonamides by the zeolite Y (adsorption equilibrium < 1 min (Braschi et al., 2010a; Blasioli et al., 2014)), the suspensions were shaken on a magnetic stirrer for $30 \mathrm{~min}$ at RT and then filtered through $0.45 \mu \mathrm{m}$ Durapore ${ }^{\circledR}$ membrane. Once the adsorption was completed, the liquid phase was analyzed by HPLC to measure the residual antibiotic concentration, whereas the loaded zeolite samples were recovered, air dried and stored before the regeneration process. The same loading procedure was followed for the regenerated zeolite samples.

\subsection{Zeolite loading from river water}

Fresh natural water was collected from an Italian river (Reno) in Bologna municipality and filtered up to $0.22 \mu \mathrm{m}$ (Millipore) before use. The water was characterized for $\mathrm{pH}(8.8)$, conductivity by a SAT conductimeter (Halosis, Italy) $\left(355.5 \mu \mathrm{S} \mathrm{cm}^{-1}\right.$ ), total organic carbon $\left(\mathrm{TOC}=1.71 \mathrm{mg} \mathrm{L}^{-1}\right.$, method ISO 8245:1999 for water quality), and total nitrogen ( $\mathrm{TN}=0.47 \mathrm{mg} \mathrm{L}^{-1}$, method CSN EN 12260 for water quality) by a Shimadzu TOC/TN analyzer (Japan).

$160 \mathrm{mg}$ of zeolite $\mathrm{Y}$ were exposed for $30 \mathrm{~min}$ to $2 \mathrm{~L}$ of the $0.22 \mu \mathrm{m}$ filtered river water spiked with a mixture of SD, SM, SC, SMX (40 mg each). The entrapped amount of sulfa drugs was evaluated by HPLC, measuring the residual antibiotic concentration in the liquid phase. Under these 
conditions, SD (2.50\% zeolite DW), SM (13.22\% zeolite DW), SC (1.42\% zeolite DW), and SMX (1.90\% zeolite DW) were simultaneously retained by the zeolite. The loaded zeolite aliquot was therefore homogenized and split into two sub-samples which were used to evaluate the effectiveness of the thermal and solvent-assisted regeneration treatments (vide infra).

\subsection{Regeneration treatments}

\subsubsection{Photolysis}

The irradiation was realized by a handmade merry-go-round Rayonet photoreactor equipped with four low-pressure mercury lamps (RPR-2537 ̊̊). Owing to maximal absorbance at $271 \mathrm{~nm}$ for SC and $267 \mathrm{~nm}$ for the other sulfa drugs, photoexperiments were carried out by irradiating at a fixed wavelength of $254 \mathrm{~nm} 10 \mathrm{~mL}$ of an aqueous suspension containing $20 \mathrm{mg}$ of loaded Y zeolite placed into a tubular quartz reactor (average irradiation intensity $=110 \mathrm{~mW} \mathrm{~cm}^{-2}$ ). The suspension homogeneity was ensured by magnetic stirring and suspension overheating was avoided by ventilation (the temperature never exceeded $40^{\circ} \mathrm{C}$ ). After 10,30 and $60 \mathrm{~min}$ irradiation, each suspension was centrifuged at $14000 \mathrm{rpm}$ for $15 \mathrm{~min}$ and the zeolite pellet was recovered, air dried, and stored in a desiccator for further analysis. Photolysis experiments were also performed on aqueous solutions of pure sulfonamides $(25 \mu \mathrm{M})$ to evaluate their reactivity to the UV light.

\subsubsection{Fenton-like reaction}

The efficacy of Fenton-like reaction was tested at two different reagent concentrations (Dec et al. 2007):

a) $10 \mathrm{mM} \mathrm{FeCl} 3$ (Carlo Erba, Italy) and $200 \mathrm{mM} \mathrm{H}_{2} \mathrm{O}_{2}(40 \% \mathrm{~m} / \mathrm{v}$, Carlo Erba, Italy);

b) $40 \mathrm{mM} \mathrm{FeCl}_{3}$ and $600 \mathrm{mM} \mathrm{H}_{2} \mathrm{O}_{2}$.

In both conditions, loaded zeolite samples $(20 \mathrm{mg})$ were suspended in $10 \mathrm{~mL} \mathrm{FeCl}_{3}$ solution and shaken at $3000 \mathrm{rpm}$ for $2 \mathrm{~h} . \mathrm{H}_{2} \mathrm{O}_{2}$ was then added drop by drop until the end of gas evolution. Under both the experimental conditions, both $\mathrm{Fe}^{3+}$ concentrations exceeded those of the sulfonamides entrapped into the zeolite (ca. 10 and 40 times) to favour the diffusion of the Fentonlike species in the zeolite cavities. The $\mathrm{pH}$ of suspension was monitored before and throughout the reaction at different times to avoid the iron hydroxide precipitation that occurs at $\mathrm{pH}>2$ at our concentrations (Pourbaix, 1949). The suspensions were left 2 additional h without further mixing, and then the zeolite was recovered through Whatman 42 filters, air dried, and stored in a desiccator for further analysis.

\subsubsection{Thermal treatment}


Samples (40 mg) of zeolite loaded with SD, SM, SC or SMX from both deionized and river water were treated in a Carlo Erba ${ }^{\circledR}$ static air furnace at different temperatures $(400,450,500,550$, and $600^{\circ} \mathrm{C}$ ) for different time durations $(1-8 \mathrm{~h})$ and stored in a dessicator for further analysis.

\subsubsection{Solvent extraction}

Several combinations of miscible solvents as Milli-Q ${ }^{\circledR}$ water, acetonitrile (HPLC grade J. T. Baker, USA), and methanol (HPLC grade Sigma-Aldrich ${ }^{\circledR}$, USA), as well as pure solvents, were tested for their ability to remove the sulfonamides from loaded zeolite $\mathrm{Y}$.

The solubility at RT of each sulfonamide in each solvent or desorption mixture was preliminary determined by adding the antibiotics to each solvent/mixture in amount exceeding those required to saturate the solution. Each suspension was then shaken, sonicated for $5 \mathrm{~min}$, filtered through a 0.45 $\mu \mathrm{m}$ Durapore membrane to eliminate the undissolved solute and the supernatant analyzed by HPLC. In Table 1 the solubility of the selected sulfonamides in the solvents/mixtures are reported. Then the volume required to solubilize the entire amount of sulfonamides loaded into the zeolite was calculated accordingly, to avoid saturation of the extractant mixtures.

$20 \mathrm{mg}$ of zeolite simultaneously loaded with SD, SM, SC, or SMX from deionized and river water were suspended in $5 \mathrm{~mL}$ of each solvent mixture. After 1, 5, 10, 20, and 30 min shaking (ca. 400 $\mathrm{rpm}$ ) at RT, each suspension was centrifuged and $1 \mathrm{~mL}$ of the liquid phase was brought to $100 \mathrm{~mL}$ with the same solvent mixture and analyzed by HPLC. The dilution was necessary to bring the sulfonamide concentration below the upper limit of the analytical calibration curve (20-200 $\mu \mathrm{M})$. The zeolite samples were then filtered, air dried, and stored in a desiccator for further analysis.

\subsection{FT-IR spectroscopy}

Infrared spectra were collected on a Tensor27 spectrometer (Bruker, MA, USA) with $4 \mathrm{~cm}^{-1}$ resolution. Self-supporting pellet $(10 \mathrm{mg}$ each) of loaded and treated zeolite were obtained with a mechanical press (SPECAC, UK) at ca. 6.5 tons $\mathrm{cm}^{-2}$ and placed into an IR cell equipped with $\mathrm{KBr}$ windows permanently attached to a vacuum line (residual pressure $\sim 1 \times 10^{-4}$ mbar), allowing sample dehydration in situ. Spectra of the bare zeolite were collected as a control.

\subsection{XRPD analysis}

XRPD patterns of thermally treated zeolites were measured on a Bruker D8 Advance Diffractometer equipped with a Sol-X detector, using $\mathrm{Cu} \mathrm{K} \alpha 1, \alpha 2$ radiation. The spectra were collected in the $3^{\circ}-110^{\circ} 2 \theta$ range with a counting time of $12 \mathrm{~s}$ step ${ }^{-1}$. Unit cell and structural parameters were determined by Rietveld profile fitting — using the GSAS package (Larson and 
Von Dreele, 2000) with the EXPGUI interface (Toby, 2001). The atomic coordinates and refinement details are given as supporting information in Table 1S.

\subsection{HPLC analysis}

The sulfonamides solubility and their concentration in the extractant mixtures were determined by HPLC-Diodarray. The chromatographic system consisted in a Jasco 880-PU Intelligent pump, a Jasco 875-UV UV-vis detector set at $271 \mathrm{~nm}$ for SC and $267 \mathrm{~nm}$ for the other antibiotics, a Jasco AS-2055 plus autosampler, Jasco ChromNAV 1.14.01 chromatography data software, a Jones Chromatography column heater 7971 , and a $4.6 \times 250 \mathrm{~mm}$ Waters Spherisorb ${ }^{\circledR} 5 \mu \mathrm{m}$ C8 analytical column kept at $35^{\circ} \mathrm{C}$. Acetonitrile and Milli- $\mathrm{Q}^{\circledR}$ water $\left(23: 77\right.$ by volume, $\mathrm{pH} 2.7$ for $\left.\mathrm{H}_{3} \mathrm{PO}_{4}\right)$ at $1 \mathrm{~mL}$ $\min ^{-1}$ was used as eluant mixture. In these conditions, the retention times for SD, SM, SC, and SMX were $4.2,5.6,6.3$, and $6.9 \mathrm{~min}$, respectively.

\subsection{TGA analysis}

Thermogravimetric and derivative thermogravimetric (TGA-DTG) analysis was performed with a TGDTA92 instrument (SETARAM, France). $20 \mathrm{mg}$ of loaded or regenerated zeolite samples were placed into an alumina crucible and heated from 30 to $700{ }^{\circ} \mathrm{C}$ at a $10{ }^{\circ} \mathrm{C} \min ^{-1}$ rate and under air flow $\left(8 \mathrm{~L} \mathrm{~h}^{-1}\right)$. The furnace was calibrated using a transition temperature of Indium. Bare zeolite $\mathrm{Y}$ was analyzed as a control.

\section{Results and Discussion}

The selected zeolite Y has been found a sorbent suitable to clean up water from sulfonamides due to its ability to embed high antibiotic amount from water with a very favorable adsorption kinetics (Braschi et al., 2010a; Braschi et al. 2013; Blasioli et al., 2014). This study is finalized to assess the most affordable technologies aimed at regenerating the zeolite once high amount of sulfonamides are entrapped into its pores and at evaluating its recyclability.

\subsection{Photolysis}

At first, the photodegradability at $254 \mathrm{~nm}$ of the pure sulfonamides in water solution was evaluated as a control and the half-life times $\left(\mathrm{t}_{1 / 2}\right)$ of the antibiotics exposed to the treatment are reported in Table 2. It is of general knowledge that the sulfonamide moiety is susceptible to photolysis (D'Souza and Day, 1968). In our conditions, the concentration of both SD and SC was halved in ca.

15 min whereas SM and SMX requested a longer exposition period (ca. 40 and $60 \mathrm{~min}$, respectively). As reported by Gao et al., 2012, SM in aqueous solution with a concentration slightly lower than that we used (20 and $25 \mu \mathrm{M}$, respectively) has been found recalcitrant to UV-light- 
activated persulfate oxidation at $254 \mathrm{~nm}$ with $10 \%$ of SM transformed after 40 min treatment. Clearly, the different photoreaction conditions reduced the SM degradation rate with respect to our conditions. Similar differences can be found in other studies (Batchu et al., 2014; Batista et al., 2014), where the $t_{1 / 2}$ of several sulfonamide antibiotics treated at $254 \mathrm{~nm}$ spans from a few minutes to about half an hour, depending on the initial antibiotic concentration and adopted conditions.

As far as the photoreactivity of the entrapped sulfonamides is concerned, Table 3 shows the amount of organic residues remained into the phototreated zeolite. TGA analysis shows that more than $90 \%$ of embedded amount was recovered unmodified after $1 \mathrm{~h}$ treatment, making thus the method useless for regeneration purpose. The persistence of the sulfonamides into the irradiated zeolite $\mathrm{Y}$ was also confirmed by infrared spectroscopy. By way of example, Figure 2 A-B shows the DTG and FTIR curves of SD-loaded zeolite before and after the UV treatment, respectively. Both the DTG curves of untreated and treated zeolites (Figure 2A, $a$ and $b$ ) present a similar profile at temperatures higher than $150^{\circ} \mathrm{C}$, thus indicating the antibiotic preservation. The peak below $150^{\circ} \mathrm{C}$ is due to water release and is present in both samples. Also the IR spectra of the same samples (Figure 2B, $a$ and $b$ ) show bands which are very similar in both the position and the intensity, thus confirming the unreactivity of the encapsulated antibiotic to UV treatment. Likely, the zeolite framework shields the embedded species from the UV radiation and/or the photoformed oxygenated species are not able to diffuse at the surface of the sulfonamide-loaded zeolite adduct.

\subsection{Fenton-like reaction}

The reactivity of the bare sulfonamides in water was evaluated under two different concentrations of $\mathrm{Fe}^{3+}$ ion and $\mathrm{H}_{2} \mathrm{O}_{2}$. Under all the conditions, the antibiotics degraded very quickly $\left(\mathrm{t}_{1 / 2}\right.$ of a few seconds, Table 2), in full agreement to the findings of Gonzales and coworkers on Fenton-degraded sulfamethoxazole (Gonzales et al., 2007).

When the Fenton-like treatments were performed on the sulfonamide-loaded zeolite, the organic residue remained into the sorbent accounted for 88-100\% of the initially loaded antibiotic amount (Table 3). DTG and IR spectra of the SD-zeolite system before and after the treatments are shown, by way of example, in Figure 2A-B. Only the IR region in the $1800-1300 \mathrm{~cm}^{-1}$ range is presented due to the absence of bands belonging to the zeolite $\mathrm{Y}$, thus favoring the simple observation of features coming from the organic species. The DTG curves of the treated and untreated zeolites revealed different features: the treated samples ( $c$ and $d$ ) present a new peak centered at about $430^{\circ} \mathrm{C}$, which accounts for $8.6 \%$ of zeolite DW and which is absent in the untreated one (curve $a$ ), thus indicating a partial formation of new more thermo-resistant species. No IR bands are clearly visible apart those assignable to $\mathrm{SD}$ in the spectra of the treated zeolites (Figure $2 \mathrm{~B}, c$ and $d$ ) (Braschi et al., 2010b). In order to better observe the features of the more thermo-stable degradation 
product(s), the Fenton-like treated SD-zeolite sample was heated $350^{\circ} \mathrm{C}$ in TGA environment. The simplified system was then newly analyzed by combined TGA and IR analysis (Figure 2A-B, curves $e$ ). The DTG shows now a single peak centered at $430^{\circ} \mathrm{C}$ thus confirming the occurrence of entrapped degradation product(s). The related IR spectrum (Figure 2B, e) reveals features typical of amorphous species which are formed by incomplete oxidation of the embedded sulfa drugs. The only partial degradation of the sulfonamides embedded into the zeolite exposed to Fenton-like treatments makes these methods unsuitable for the zeolite regeneration. The adsorption of iron species by zeolite Y could be excluded because of the negligible cation exchange capacity of the sorbent with a $\mathrm{SiO}_{2} / \mathrm{Al}_{2} \mathrm{O}_{3}$ ratio of 200 . Likely, the radical oxygenated species (mainly ${ }^{\circ} \mathrm{OH}$ and 'OOH, (Laine and Cheng, 2007)) cannot easily diffuse into the sulfonamide-loaded zeolite.

\subsection{Thermal treatment}

High silica zeolites are usually stable when thermally regenerated in air, thus preserving their adsorption properties (Khalid et al., 2004; Vignola et al., 2011a; Vignola et al., 2011b). Due to the importance of discovering both the least time- and energy-consuming strategies to clean up zeolites used to clean up waters from sulfonamides, a detailed assessment devoted specifically to identifying the best thermal regeneration conditions is here presented. The amount of organic residues remained into loaded zeolite samples exposed to different temperatures for different time durations was evaluated by TGA analysis. For the sake of brevity, only the thermal regeneration of SMXloaded zeolite is reported in Figure 3. According to residual amount of sulfonamides in the treated zeolite, $4 \mathrm{~h}$ at $500^{\circ} \mathrm{C}$ were identified as the best regeneration conditions for all the selected sulfonamides (organic residue $=0.18 \%$ zeolite DW, on average). The structural features of treated zeolites were evaluated by XRPD (Figure 4). In the figure, the diffraction pattern from the same zeolite after SMX adsorption (Leardini et al. 2014) which has been measured at the European Synchrotron Radiation Facility is reported. In this last case the X-ray beam wavelength was $0.653 \AA$, almost the half of the CuK- $\alpha$ wavelength (1.544 $\AA$ ) used for our XRD measurements. Consequently, for a better comparison all the diffraction patterns are reported as a function of the $d$-spacing. At the same time, the diffraction peak positions are quite similar among samples, and consequently, unitcell parameters are not significantly modified as shown in Table 4 . The heating process does not affect the zeolite crystallinity and the diffraction patterns of regenerated samples regain almost perfectly the features of unloaded material. By virtue of its high flexibility and stability (Alberti and Martucci, 2005), the FAU framework is able to slightly distort and relieve the strain imposed by the regeneration as demonstrated by the Crystallographic Free Area (C.F.A) (Baerlocher et al., 2007) and channel's ellipticity values which are similar to those reported for the bare material (Table 4). 
These results highlighted the $\mathrm{Y}$ ability to modify the dimensions of the internal void volume for size and shape dependent sorption behavior.

The adsorption capacity of the thermally treated zeolite samples was tested through their application in several adsorption/regeneration cycles. In Figure 5, three adsorption/regeneration cycles were performed on the zeolite toward SD, SM, and SC antibiotics whereas the recycle was repeated up to six times toward SMX.

For each investigated sulfonamides, the adsorption capacity of treated zeolite samples resulted very close to the initial loading capacity, thus making these conditions ( $4 \mathrm{~h}$ at $500^{\circ} \mathrm{C}$ ) suitable for zeolite regeneration. Interestingly, the first adsorption after regeneration is higher $(+12 \%$, on average) for three out of four sulfonamide-loaded systems. These findings can be explained by a partial modification of the zeolite silanol groups that are condensed by the thermal treatment (Braschi et al., 2012), thus making the sorbent more organophilic, as well as by a low reproducibility of such a complex multistep experiment.

When the treatment was applied to the zeolite exposed to the river water simultaneously spiked with the four sulfa drugs, the antibiotic adsorption was found at $83 \%$ of the initial loading capacity, on average, as shown by the HPLC reported in Table 5. It should be noted that the HPLC data are specifically related to the sulfa drug loading, whereas the TGA measurements are referred to the total organic species embedded into the pores. The difference between TGA and HPLC data can be ascribed to the embedding into the pores of a small amount of organic species occurring in the natural water.

\subsection{Solvent extraction}

The sulfonamide-loaded zeolites were exposed to desorption treatments. Two protic solvents (water and methanol) as well as an aprotic one (acetonitrile) were selected for the molecular dimensions compatible with the cage access window dimension (i.e. $7.0 \AA \times 7.1 \AA$ ) and for their different polarity. The pure solvents and their binary and ternary mixtures were evaluated to test their ability to displace antibiotics from the zeolite cages. In Table 6, the sulfonamides remained into zeolite Y after 30 min extraction are reported as a percentage of loaded amount. Some relevant error values (expressed as absolute error) are due to the complexity of the loading/extraction steps followed by the extractant dilution which is necessary to bring the sulfonamide concentration below the upper limit of the analytical calibration curve $(20-200 \mu \mathrm{M})$.

The amount of embedded sulfonamides was found almost unmodified after water extraction (94\% of loaded sulfonamide, on average) in agreement with the irreversibility of the sulfonamide adsorption process by the zeolite Y (Braschi et al., 2010a; Blasioli et al., 2014). Similarly, when loaded zeolite samples were exposed to pure acetonitrile, SD, SM, and SC were still recovered in 
high amounts (89\% loaded sulfonamide, on average) after the treatment, whereas about $41 \%$ of SMX remained into the zeolite pores, thus making acetonitrile unsuitable for regeneration purpose. With pure methanol, the sulfonamide extraction efficiency was in the order: SD > SC > SM > SMX but still far to be acceptable. SD was more easily removed from the zeolite than SMX, regardless the higher methanol solubility of the latter than SD (28.0 and $4.4 \mathrm{mM}$, respectively, Table 1). Likely, the extraction efficacy depends not only on the solvation of guest molecules but on the affinity between the extractant and zeolite framework as well. When sulfonamide-loaded zeolite samples were treated with water/acetonitrile or water/methanol binary mixtures, the amount remained entrapped into the zeolite porosities was quite different among the sulfonamides, and still accounted for 16 and $26 \%$ of loaded sulfonamide on average, respectively. The best regeneration was obtained with the ternary $\mathrm{H}_{2} \mathrm{O} / \mathrm{CH}_{3} \mathrm{CN} / \mathrm{CH}_{3} \mathrm{OH}$ mixture, which allowed to remove the highest drug amount (8\% of loaded sulfonamides remained entrapped, on average, roughly corresponding to $1.8 \%$ zeolite DW). Also the extraction power of water at $\mathrm{pH} 8.5$ was evaluated as a component of the ternary mixture, due to the acidic nature of sulfonamides ( $K_{a}$ values, Figure 1). Surprisingly, in these conditions, the antibiotic amount that remained embedded into the zeolite increased to about $13 \%$ loaded amount, on average. Likely, with the exception of SM, the polarization of water molecules surrounding hydroxide ions affects the intermolecular interactions among the solvents with a reduction, as a general result, of the solvating and displacement properties toward the sulfonamides.

FT-IR spectra of sulfonamide loaded zeolite samples exposed to the neutral ternary mixture for different time durations were recorded to evaluate the desorption time needed to remove the sulfonamides from zeolite $\mathrm{Y}$. This technique is not considered the optimal to study the spectral features of low amount of matrix-dispersed organic compounds since it is generally accepted that amounts smaller than 1-3\% matrix DW cannot be appreciated. Nevertheless, due to the high drug loading, the technique was considered suitable to evaluate the extraction kinetics of the selected sulfonamides. In Figure 6, IR spectra of sulfonamide-loaded zeolite Y samples (curves $a$ ), along with those of samples extracted for different time durations $(b-e)$, are reported. The IR absorptions of each single sulfonamide (spectra $a$ ) are well visible as expected by the high amount embedded (22\% zeolite DW, on average) (Braschi et al., 2010a; Blasioli et al., 2014). The assignment of the main bands of the embedded antibiotics and related interactions with the zeolite adsorption sites have been detailed elsewhere (Blasioli at al., 2014; Braschi et al., 2010b). Already after $1 \mathrm{~min}$ extraction (curves $b$ ), no signal assignable to SM, SC or SMX structures can be observed, thus ensuring their complete removal from the zeolite matrix. Interestingly, in the case of SD-loaded zeolite, antibiotic bands are clearly visible after 1 and 5 min extraction ( $b$ and $c$, respectively) but 
disappear after 10 min treatment (curve $d$ ). These findings indicate that the SD extraction kinetics is unfavoured if compared to those of the other sulfonamides. This can be explained through the occurrence of bulky SD dimers embedded into the zeolite cage as recently reported for small sized sulfonamide antibiotics (Braschi et al., 2010b; Braschi et al., 2013). The extra stabilization of the dimer inside the cage due to the occurrence of two medium strength H-bonds, along with the reduction of room available for solvent molecules to displace SD dimers from the cage wall, make this sulfonamide the last to be desorbed on a time scale. For this reason, at least $10 \mathrm{~min}$ of contact time has to be considered to completely regenerate sulfonamide-loaded zeolite $\mathrm{Y}$ by extraction. The absence of infrared signals assignable to organic species (Figure 6) places all the sulfonamide residues below 1-3\% zeolite DW, making thus this method suitable for zeolite Y regeneration.

When the treatment was applied to the zeolite exposed to the river water simultaneously spiked with sulfa drugs, the drug adsorption was found at $77 \%$ of the initial loading capacity, on average, as shown by the HPLC data reported in Table 5. Similarly to what it was already observed for the thermal treatment, the difference between TGA and HPLC data can be ascribed to the embedding into the zeolite pores of a small amount of organic species occurring in the natural water.

\section{Conclusions}

An high silica zeolite Y loaded with sulfadiazine, sulfamethazine, sulfachloropyridazine, and sulfamethoxazole was exposed to several regeneration techniques. Chemical processes (photolysis, Fenton-like reaction) did not allow the regeneration of sulfonamide-loaded zeolite Y. In particular, the adopted photolysis conditions did not affect neither the quantity nor the structure of the embedded sulfonamides, whereas Fenton-like process only partially transformed the entrapped antibiotic molecules with no significant reduction of the loaded amount.

On the contrary, both the thermal treatment and solvent extraction were successful in the complete regeneration of loaded zeolite samples. As far as the thermal regeneration is considered, the best results were obtained when loaded zeolite samples were exposed to $500{ }^{\circ} \mathrm{C}$ for $4 \mathrm{~h}$. Thermogravimetric analysis (TGA/DTG) and infrared (FT-IR) spectroscopy were used to monitor the evolution of guest transformations, if present, and changes in the loaded amount. The ability of zeolite $\mathrm{Y}$ to regain its original structural features was defined by XRPD investigations on thermally treated and untreated samples, regardless of the sulfonamide considered. The high flexibility and thermal stability of the zeolite Y was confirmed by its reuse in several adsorption/thermal treatment cycles with no significant changes in the loading capacity.

A feasibility study on solvent extraction of sulfonamides from zeolite pores was also conducted with solvent mixtures of different composition and $\mathrm{pH}$. Several combinations of water, acetonitrile, 
and methanol were used to remove all the four sulfonamides from the loaded zeolite samples. In general, the mixture with the best affinity for the zeolite and with the best solving properties for the sulfonamides was composed by equal amounts of acetonitrile, methanol and water at $\mathrm{pH}$ 7. The extraction from the zeolite cage of singly embedded sulfonamide molecules (as in the case of sulfamethazine, sulfachloropyridazine, and sulfamethoxazole) was immediate (1 min contact was enough to completely remove the antibiotics) whereas a contact time of at least 10 min was requested to displace those retained as dimeric species (as in the case of sulfadiazine).

Due to the good recyclability of the exhausted sorbent even when applied to clean up natural river water spiked with a mixture of the four sulfa drugs, the zeolite-based water treatment here presented can be considered an affordable technology.

Although nowadays great efforts have to be done to develop environmental strategies alternative to solvent-based or energy-consuming processes, a problem as the world-wide diffusion of bacterial antibiotic resistance induced by antibiotics still needs to be addressed. The thermal treatment and the solvent extraction here presented allow a full recyclability of a sorbent material with an excellent ability to entrap sulfonamides from water. This zeolite-based technology can be easily adopted to reduce the point source sulfonamide pollution as that represented by wastewaters coming from fish farms and hospitals.

\section{Acknowledgements}

Research co-funded by the Italian Ministry of Education, University, and Research (Project PRIN 2008 BL2NWK: Zeolites as nano-reactors for the environment: efficiency, selectivity and stability in the adsorption of drugs from contaminated waters).

\section{References}

Acar, J., Rostel, B., 2001. Antimicrobial resistance: an overview. Rev. Sci. Tech. 20, 797-810.

Ahmaruzzaman, M., 2008. Adsorption of phenolic compounds on low-cost adsorbents: A review. Advances in Colloid and Interface Science 143, 48-67.

Alberti, A. and Martucci, M., 2005. Phase transformations and structural modifications induced by heating in microporous materials. A. Gamba, C. Colella and S. Coluccia (Editors), Studies in Surface Science and Catalysis, Elsevier, Vol 155, p. 19-43.

Baerlocher, Ch., McCusker, L. B., Olson, D. H. , 2007. Atlas of Zeolite Framework Types. 6th ed., Elsevier, Amsterdam. 
Batchu, S. R., Panditi, V. R., Gardinali, P. L., 2014. Photodegradation of sulfonamide antibiotics in simulated and natural sunlight: Implications for their environmental fate. J. Environ. Sci. Health, Part B: Pesticides, Food Contaminants, and Agricultural Wastes 49 (3), 200-211.

Batista, A. P. S., Pires, F. C. C., Teixeira, A. C. S. C., 2014. Photochemical degradation of sulfadiazine, sulfamerazine and sulfamethazine: Relevance of concentration and heterocyclic aromatic groups to degradation kinetics. Journal of Photochemistry and Photobiology A: Chemistry 286, 40-46.

Bish D. L. and Ming D. W. (Editors), 2001. Natural Zeolites: Occurrence, Properties, Applications, Reviews in Mineralogy \& Geochemistry. Vol 45, Mineralogical Society of America and the Geochemical Society, Washington, DC.

Blasioli, S., Martucci, A., Paul, G., Gigli, L., Cossi, M., Johnston, C. T., Marchese, L., Braschi, I., 2014. Removal of sulfamethoxazole sulfonamide antibiotic from water by high silica zeolites: A study of the involved host-guest interactions by a combined structural, spectroscopic, and computational approach. J. Colloid and Interface Science 419, 148-159.

Braschi, I., Blasioli, S., Gigli, L., Gessa, C. E., Alberti, A., Martucci, A., 2010a. Removal of sulfonamide antibiotics from water: Evidence of adsorption into an organophilic zeolite $\mathrm{Y}$ by its structural modifications. J. Hazardous Materials 178, 218-225.

Braschi, I., Gatti, G., Paul, G., Gessa, C. E., Cossi, M., Marchese, L., 2010b. Sulfonamide antibiotics embedded in high silica zeolite Y: A combined experimental and theoretical study of host-guest and guest-guest interactions. Langmuir 26 (12), 9524-9532.

Braschi, I., Gatti, G., Bisio, C., Berlier, G., Sacchetto, V., Cossi, M., Marchese, L., 2012. The role of silanols in the interactions between methyl tert-butyl ether and high silica faujasite $\mathrm{Y}$ : an infrared spectroscopy and computational model study. Phys. Chem. C 116 (2012) 6943-6952.

Braschi, I., Paul, G., Gatti, G., Cossi, M., Marchese, L., 2013. Embedding monomers and dimers of sulfonamide antibiotics into high silica zeolite Y: an experimental and computational study of the tautomeric forms involved. RSC Advances 3, 7427-7437.

Cooney, D. O., 1999. Adsorption design for wastewater treatment. Lewis Publishers, London, England, UK.

D’Souza L. and Day R. A., 1968. Photolytic cleavage of sulfonamide bonds. Science, 160, 882-883.

Dec, J., Bruns, M. A., Cai, L., Koziel, J. A., Snyder, E. M., Kephart, K. B., Watson J. E., 2007. Removal of odorants from animal waste using Fenton's reaction. Proceedings of the International symposium on air quality and waste management for agriculture, 16-19 September 2007, Broomfield, Colorado (USA). 
Feng, W. and Nansheng, D., 2000. Photochemistry of hydrolytic iron (III) species and photoinduced degradation of organic compounds. A minireview. Chemosphere 41, 1137-1147.

Fukahori, S., Fujiwara, T., Ito, R., Funamizu, N., 2011. pH-Dependent adsorption of sulfa drugs on high silica zeolite: Modeling and kinetic study. Desalination 275 237-242.

Gao, P., Munir, M., Xagoraraki, I., 2012. Correlation of tetracycline and sulfonamide antibiotics with corresponding resistance genes and resistant bacteria in a conventional municipal wastewater treatment plant. Science of the Total Environment 421-422, 173-183.

Gao, Y.-q., Gao, N.-y., Deng, Y., Yang, Y.-q., Ma, Y., 2012. Ultraviolet (UV) light-activated persulfate oxidation of sulfamethazine in water. Chemical Engineering Journal 195-196, 248253.

Gonzalez, O., Sans, C., Esplugas, S., 2007. Sulfamethoxazole abatement by photo-Fenton: Toxicity, inhibition and biodegradability assessment of intermediates. J. Hazard. Mater. 146, 459-464.

Kesraoui-Ouki, S., Cheeseman, C. R., Perry, R., 1994. Natural zeolite utilization in pollution control: a review of applications to metals' effluents. J. Chem. Tech. Biotechnol. 59, 121-126.

Khalid, M., Joly, G., Renaud, A., Magnoux, P., 2004. Removal of phenol from water by adsorption using zeolites. Industrial \& Engineering Chemistry Research 43, 5275-5280.

Laine, D. F. and Cheng, I. F., 2007. The destruction of organic pollutants under mild reaction conditions: A review. Microchemical Journal 85, 183-193.

Larson, A. C. and Von Dreele, R. B., 2000. General Structure Analysis System (GSAS), Los Alamos National Laboratory Report LAUR, 86-748.

Leardini, L., Martucci, A., Braschi, I., Blasioli, S., Quartieri, S., 2014. Regeneration of high-silica zeolites after sulfamethoxazole antibiotic adsorption: a combined in situ high-temperature synchrotron powder X-ray diffraction and thermal degradation study. Mineralogical Magazine 78 (5), 1141-1159.

Leng C.-C. and Pinto, N. G., 1996. An investigation of the mechanisms of chemical regeneration of activated carbon. Ind. Eng. Chem. Res. 35, 2024-2031.

Lindsey, M.E., Meyer, M., Thurman, E.M., 2001. Analysis of trace levels of sulfonamide and tetracycline antimicrobials in groundwater and surface water using solid- phase extraction and liquid chromatography/mass spectrometry. Anal. Chem. 73, 4640-4646.

Martucci, A., Braschi, I., Marchese, L., Quartieri, S., 2014. Recent advances in clean-up strategies of waters polluted with sulfonamide antibiotics: a review of sorbents and related properties. Mineralogical Magazine 78 (5), 1115-1140. 
Martucci, A., Pasti, L., Marchetti, N., Cavazzini, A., Dondi, F., Alberti, A., 2012. Adsorption of pharmaceuticals from aqueous solutions on synthetic zeolites. Microporous and Mesoporous Materials 148, 174-184.

Nahm, S. W., Shim, W. G., Park, Y.-K., Kim, S. C., 2012. Thermal and chemical regeneration of spent activated carbon and its adsorption property for toluene. Chemical Engineering Journal 210, 500-509.

Navalon, S., Alvaro, M., Garcia, H., 2009. Highly dealuminated Y zeolite as efficient adsorbent for the hydrophobic fraction from wastewater treatment plants effluents, Journal of Hazardous Materials 166, 553-560.

Pourbaix, M. J. N., 1949. Thermodynamics of dilute aqueous solutions, Edward Arnold and Co., London, England, UK, 136 p...

Rivas, F. J., 2006. Polycyclic aromatic hydrocarbons sorbed on soils: A short review of chemical oxidation based treatments. Journal of Hazardous Materials B138, 234-251.

Rivera-Utrilla, J., Sánchez-Polo, M., Ferro-García, M. Á., Prados-Joya, G., Ocampo-Pérez, R., 2013. Pharmaceuticals as emerging contaminants and their removal from water. A review. Chemosphere 93, 1268-1287.

Rivera-Utrilla, J., Sánchez-Polo, M., Ferro-García, M. Á., Prados-Joya, G., Ocampo-Pérez, R., 2013. Pharmaceuticals as emerging contaminants and their removal from water. A review. Chemosphere 93, 1268-1287.

Rossner, A., Snyder, S. A., Knappe, D. R. U., 2009. Removal of emerging contaminants of concern by alternative adsorbents. Water Research 43, 3787-3796.

Toby, B. H., 2001. EXPGUI, a graphical user interface for GSAS. J. Appl. Cryst. 34, 210-213.

Tsai, W.-T., Hsu, H.-C., Su, T.-Y., Lin, K.-Y., Lin, C.-M., 2006. Adsorption characteristics of bisphenol-A in aqueous solutions onto hydrophobic zeolite. Journal of Colloid and Interface Science 299 513-519.

Ungemach, F.R., 2012. Figures on quantities of antibacterials used for different purposes in the EU countries and interpretation. Acta Vet. Scand. Suppl. 93, 89-98.

van der Ven, A. J. A. M., Mantel, M. A., Vree, T. B., Koopmans, P. P., van der Meer, J. W. M., 1994. Formation and elimination of sulphamethoxazole hydroxylamine after oral administration of sulphamethoxazole. Brit. J. Clin. Pharm. 38 (1994) 147-150.

van der Ven, A. J. A. M., Vree, T. B., van Ewijk-Benken Kolmer, W. J., Koopmans, P. P., van der Meer, J. W. M., 1995. Urinary recovery and kinetics of sulphamethoxazole and its metabolites in HIV-seropositive patients and healthy volunteers after a single oral dose of sulphamethoxazole. Brit. J. Clin. Pharm. 39, 621-625. 
Vignola, R., Bagatin, R., De Folly D’Auris, A., Flego, C., Nalli, M., Ghisletti, D., Millini, R., Sisto, R., 2011a. Zeolites in a permeable reactive barrier (PRB): One year of field experience in a refinery groundwater - Part 1: The performances. Chem. Eng. J. 178, 204-209.

Vignola, R., Bagatin, R., De Folly D’Auris, A., Previde Massara, E., Ghisletti, D., Millini, R., Sisto, R., 2011b. Zeolites in a permeable reactive barrier (PRB): One-year of field experience in a refinery groundwater. Part 2: Zeolite characterization. Chem. Eng. J. 178, 210 
Table 1. Solubility of the selected sulfonamides in solvent mixtures with different composition

\begin{tabular}{lcccccc}
\hline & \multicolumn{5}{c}{ Solubility } \\
Sulfonamide & \multicolumn{5}{c}{$\mathrm{mM}$} \\
\cline { 2 - 7 } & \multicolumn{7}{c}{$\mathrm{H}_{2} \mathrm{O} / \mathrm{CH}_{3} \mathrm{CN} / \mathrm{CH}_{3} \mathrm{OH}$ volume ratio } \\
\cline { 2 - 7 } & $100 / 0 / 0$ & $0 / 100 / 0$ & $0 / 0 / 100$ & $50 / 50 / 0$ & $50 / 0 / 50$ & $33 / 33 / 33$ \\
\hline SD & $0.072(0.005)$ & $3.9(0.2)$ & $4.4(0.4)$ & $8.7(1.3)$ & $1.9(0.1)$ & $7.7(0.1)$ \\
SM & $0.138(0.004)$ & $53.2(3.0)$ & $33.9(11.1)$ & $64.6(5.6)$ & $14.0(2.7)$ & $57.8(2.5)$ \\
SC & $0.176(0.007)$ & $158.8(12.9)$ & $43.7(17.3)$ & $100.8(2.6)$ & $12.7(3.6)$ & $90.5(7.5)$ \\
SMX & $0.203(0.002)$ & $73.9(9.7)$ & $28.0(3.8)$ & $22.2(4.5)$ & $11.4(2.1)$ & $275.5(17.9)$ \\
\hline
\end{tabular}

In brackets the standard deviation. 
Table 2. Half-life times $\left(\mathrm{t}_{1 / 2}\right)$ of the selected sulfonamides in water solution $(25 \mu \mathrm{M})$ exposed to several chemical treatments.

\begin{tabular}{lcccc}
\hline \multirow{2}{*}{ Treatment } & \multicolumn{4}{c}{$\mathbf{t}_{\mathbf{1} / \mathbf{2}}$ (min) } \\
\cline { 2 - 5 } & SD & SM & SC & SMX \\
\hline Photolysis & 12 & 39 & 16 & 60 \\
Fenton-like $^{a}$ & $<0.1$ & $<0.1$ & $<0.1$ & $<0.1$ \\
Fenton-like $^{b}$ & $<0.1$ & $<0.1$ & $<0.1$ & $<0.1$ \\
\hline${ }^{\mathrm{a}} 10 \mathrm{mM} \mathrm{FeCl}_{3}+200 \mathrm{mM} \mathrm{H}_{2} \mathrm{O}_{2} ;{ }^{\mathrm{b}} 40 \mathrm{mM} \mathrm{FeCl}_{3}+600 \mathrm{mM} \mathrm{H}_{2} \mathrm{O}_{2}$.
\end{tabular}


Table 3. Organic residue remained into the zeolite $Y$ exposed to several regeneration chemical treatments as determined by TGA analysis (exposition time: $60 \mathrm{~min}$ ).

\begin{tabular}{|c|c|c|c|c|}
\hline \multirow{2}{*}{ Regeneration method } & \multicolumn{4}{|c|}{ Organic residue as a $\%$ of loaded antibiotic amount } \\
\hline & SD & SM & SC & SMX \\
\hline Photolysis & $95.3(1.2)$ & $96.0(1.6)$ & $93.0(3.6)$ & $95.1(1.0)$ \\
\hline Fenton-like ${ }^{b}$ & $100.0(0.0)$ & $98.6(0.1)$ & $98.1(0.0)$ & $97.0(0.1)$ \\
\hline Fenton-like ${ }^{b}$ & $89.7(0.1)$ & $87.8(0.0)$ & $96.9(0.1)$ & $97.5(0.4)$ \\
\hline
\end{tabular}

In brackets the absolute error. 
Table 4. Unit cell parameters, Crystallographic Free Area (C.F.A.) sensu Baerlocher et al. (2007) and channel's ellipticity ( $\varepsilon$, defined as the ratio between the larger and the smaller O-O diameters) for zeolite Y loaded with SD, SM, SC and SMX before and after $4 \mathrm{~h}$ at $500^{\circ} \mathrm{C}$.

\begin{tabular}{lccccc}
\hline Parameter & $\mathbf{Y}^{\mathbf{a}}$ & $\mathbf{Y - S D}$ & $\mathbf{Y - S M}$ & $\mathbf{Y - S C}$ & Y-SMX $^{\mathbf{b}}$ \\
\hline $\mathbf{a}(\AA)$ & $24.259(1)$ & $24.273(1)$ & $24.281(1)$ & $24.280(1)$ & $24.257(1)$ \\
$\mathbf{b}(\AA)$ & $24.259(1)$ & $24.273(1)$ & $24.281(1)$ & $24.280(1)$ & $24.257(1)$ \\
$\mathbf{c}(\AA)$ & $24.259(1)$ & $24.273(1)$ & $24.281(1)$ & $24.280(1)$ & $24.257(1)$ \\
$\mathbf{V}\left(\AA^{\mathbf{3}}\right)$ & $14277.1(1)$ & $14301.0(9)$ & $14314.3(3)$ & $14313.1(3)$ & $14272.6(4)$ \\
$\mathbf{C F A}\left(\AA^{\mathbf{2}}\right)$ & 39.07 & 41.60 & 39.57 & 39.57 & 41.99 \\
$\boldsymbol{\varepsilon}$ & 1.01 & 1.01 & 1.02 & 1.02 & 1.02 \\
\hline
\end{tabular}

${ }^{\mathrm{a}}$ As reported in Braschi et al. (2010a); ${ }^{\mathrm{b}}$ As reported in Leardini et al. (2014).

In brackets the digit affected by error. 
Table 5. Evaluation of the loading capacity of zeolite $Y$ toward a mixture of sulfa drugs added to a river water after thermal and solvent-assisted regeneration treatments

Loading of sulfa drugs by zeolite Y as a \% of zeolite DW

Regeneration treatment HPLC data (TGA data)

\begin{tabular}{lccccc}
\cline { 2 - 5 } & SD & SM & SC & SMX & Total sulfa drugs \\
\hline No treatment & 2.5 & 13.2 & 1.4 & 1.9 & $19.1(19.9)$ \\
Thermally regenerated & 1.9 & 10.8 & 0.7 & 2.2 & $15.7(17.2)$ \\
Desorbed with solvent & 1.6 & 11.1 & 0.4 & 1.6 & $14.6(18.1)$ \\
\hline
\end{tabular}

Sulfa drug concentration (40 $\mathrm{mg} \mathrm{L}^{-1}$ each) in fresh river water ( $\left.\mathrm{pH} 8.8\right)$ 
Table 6. Residual sulfonamides remained into the zeolite $Y$ exposed to selected extractant mixtures obtained by HPLC analysis (contact time: $30 \mathrm{~min}$ ).

\begin{tabular}{ccccc}
\hline $\mathrm{H}_{2} \mathrm{O} / \mathrm{CH}_{3} \mathrm{CN} / \mathrm{CH}_{3} \mathrm{OH}$ & \multicolumn{4}{c}{ Residual sulfonamide as a $\%$ of initial zeolite loading } \\
\cline { 2 - 5 } volume ratio & $S D$ & $S M$ & $S C$ & $S M X$ \\
\hline $100 / 0 / 0$ & $94.6(0.3)$ & $93.8(0.6)$ & $92.7(0.4)$ & $96.1(0.1)$ \\
$0 / 100 / 0$ & $89.4(0.4)$ & $87.6(0.01)$ & $88.7(0.5)$ & $40.8(19.6)$ \\
$0 / 0 / 100$ & $4.0(3.1)$ & $18.8(4.6)$ & $11.3(3.5)$ & $31.4(7.3)$ \\
$50 / 50 / 0$ & $0.0(0.9)$ & $13.8(1.4)$ & $27.0(1.9)$ & $23.8(0.6)$ \\
$50 / 0 / 50$ & $5.4(4.3)$ & $14.8(0.4)$ & $53.1(1.7)$ & $31.9(5.4)$ \\
$33 / 33 / 33$ & $0.5(4.5)$ & $10.4(11.8)$ & $11.4(0.3)$ & $8.8(10.4)$ \\
$33 / 33 / 33^{\mathrm{a}}$ & $9.3(5.0)$ & $3.7(3.4)$ & $14.5(3.0)$ & $22.7(4.0)$ \\
\hline
\end{tabular}

${ }^{\mathrm{a}} \mathrm{pH} 9.5$ for $0.1 \mathrm{M} \mathrm{KOH}$. In brackets the absolute error. 


\section{Figure captions}

Figure 1. Chemical structures and $p K_{a}$ of the four selected sulfonamides.

Figure 2. (A) DTG curves and (B) FT-IR spectra of zeolite Y loaded with SD before $a$ ) and after photolysis $b$ ), Fenton-like treatment at $10 \mathrm{mM} \mathrm{FeCl}_{3}+200 \mathrm{mM} \mathrm{H}_{2} \mathrm{O}_{2} c$ ) and at $40 \mathrm{mM} \mathrm{FeCl}_{3}+600$ $\mathrm{mM} \mathrm{H}_{2} \mathrm{O}_{2} d$ ). DTG and IR features of Fenton-like treated SD-loaded zeolite heated up to $350^{\circ} \mathrm{C}$ and of bare zeolite are also reported ( $e$ and $f)$.

Figure 3. Organic residues remained into SMX loaded-zeolite Y thermally treated under different temperatures and time durations. The least energy-consuming conditions are circled: $4 \mathrm{~h}$ at $500^{\circ} \mathrm{C}$.

Figure 4. Normalized powder diffraction patterns of thermally treated $\left(4 \mathrm{~h}\right.$ at $\left.500^{\circ} \mathrm{C}\right)$ zeolite samples previously loaded with sulfonamides (Y-SM, Y-SD, Y-SC, Y-SMX). XRPD of untreated zeolite $\mathrm{Y}(\mathrm{Y})$ is reported as a comparison (the stacked plots have been shifted for easy comparison). * As reported in Braschi et al. (2010a); ** As reported in Leardini et al. (2014) after background subtraction $(\lambda=0.653 \AA)$.

Figure 5. Adsorption capacity of zeolite $\mathrm{Y}$ toward sulfonamides after several adsorption/regeneration cycles (regeneration: $4 \mathrm{~h}$ at $500^{\circ} \mathrm{C}$ ).

Figure 6. FTIR spectra of high silica zeolite Y loaded with sulfadiazine (SD), sulfamethazine (SM), sulfachloropyridazine (SC), and sulfamethoxazole (SMX) before (a) and after extraction with $\mathrm{CH}_{3} \mathrm{CN} / \mathrm{CH}_{3} \mathrm{OH} / \mathrm{H}_{2} \mathrm{O}=33 / 33 / 33 \%$ volume ratio. Extraction durations: (b) 1 , (c) 5, (d) 10, (e) 20 $\min$. 


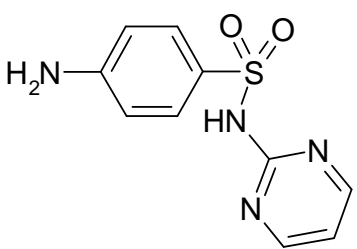

sulfadiazine (SD) $\mathrm{pK}_{\mathrm{a}}=6.4$

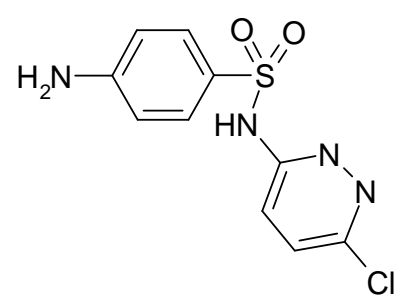

sulfachloropyridazine (SC) $\mathrm{pK}_{\mathrm{a}}=5.5$

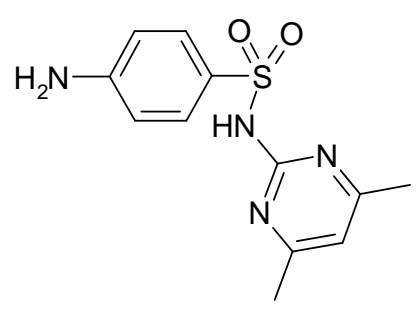

sulfamethazine (SM) $\mathrm{pK}_{\mathrm{a}}=7.5$

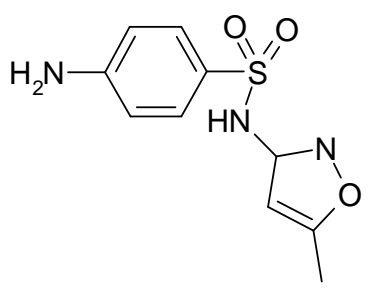

sulfamethoxazole (SMX) $\mathrm{pK}_{\mathrm{a}}=5.7$

Figure 1. 

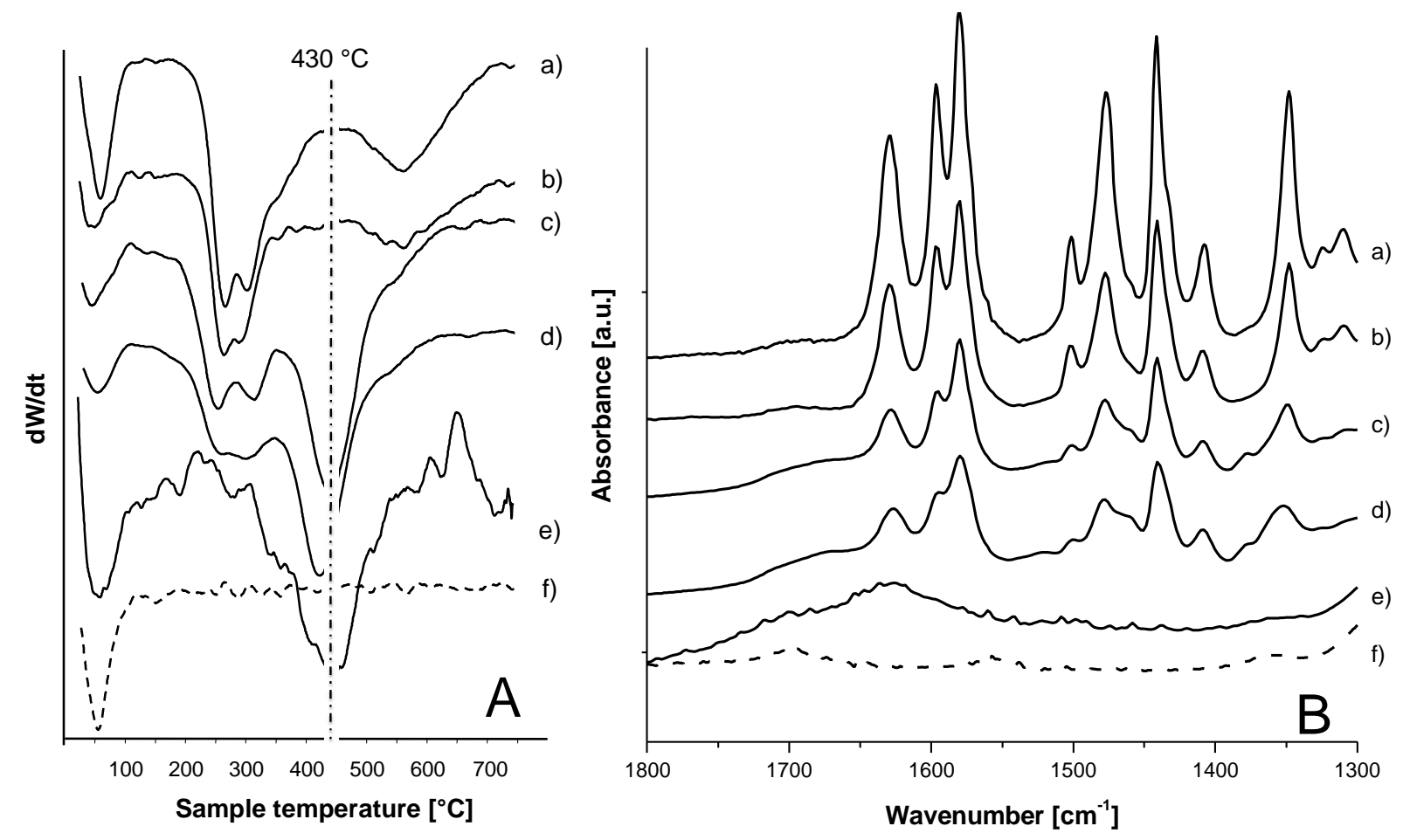

Figure 2. DTG curves and (B) FT-IR spectra of zeolite Y loaded with SD before $a$ ) and after photolysis $b$ ), Fenton-like treatment at $10 \mathrm{mM} \mathrm{FeCl}_{3}+200 \mathrm{mM} \mathrm{H}_{2} \mathrm{O}_{2} c$ ) and at $40 \mathrm{mM} \mathrm{FeCl} 3+600$ $\mathrm{mM} \mathrm{H}_{2} \mathrm{O}_{2} d$ ). DTG and IR features of Fenton-like treated SD-loaded zeolite heated up to $350^{\circ} \mathrm{C}$ and of bare zeolite are also reported ( $e$ and $f$ ). 


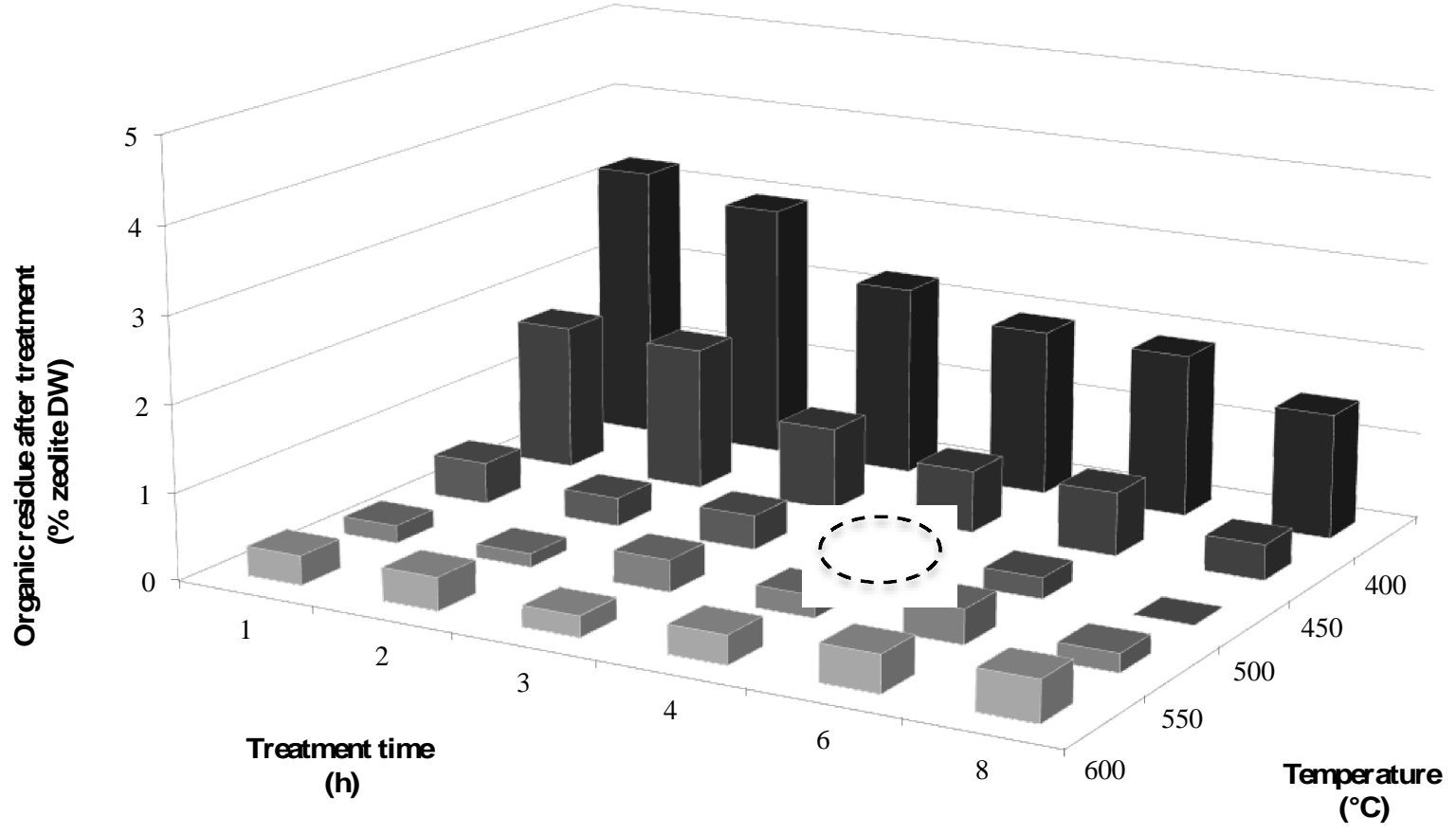

Figure 3. 


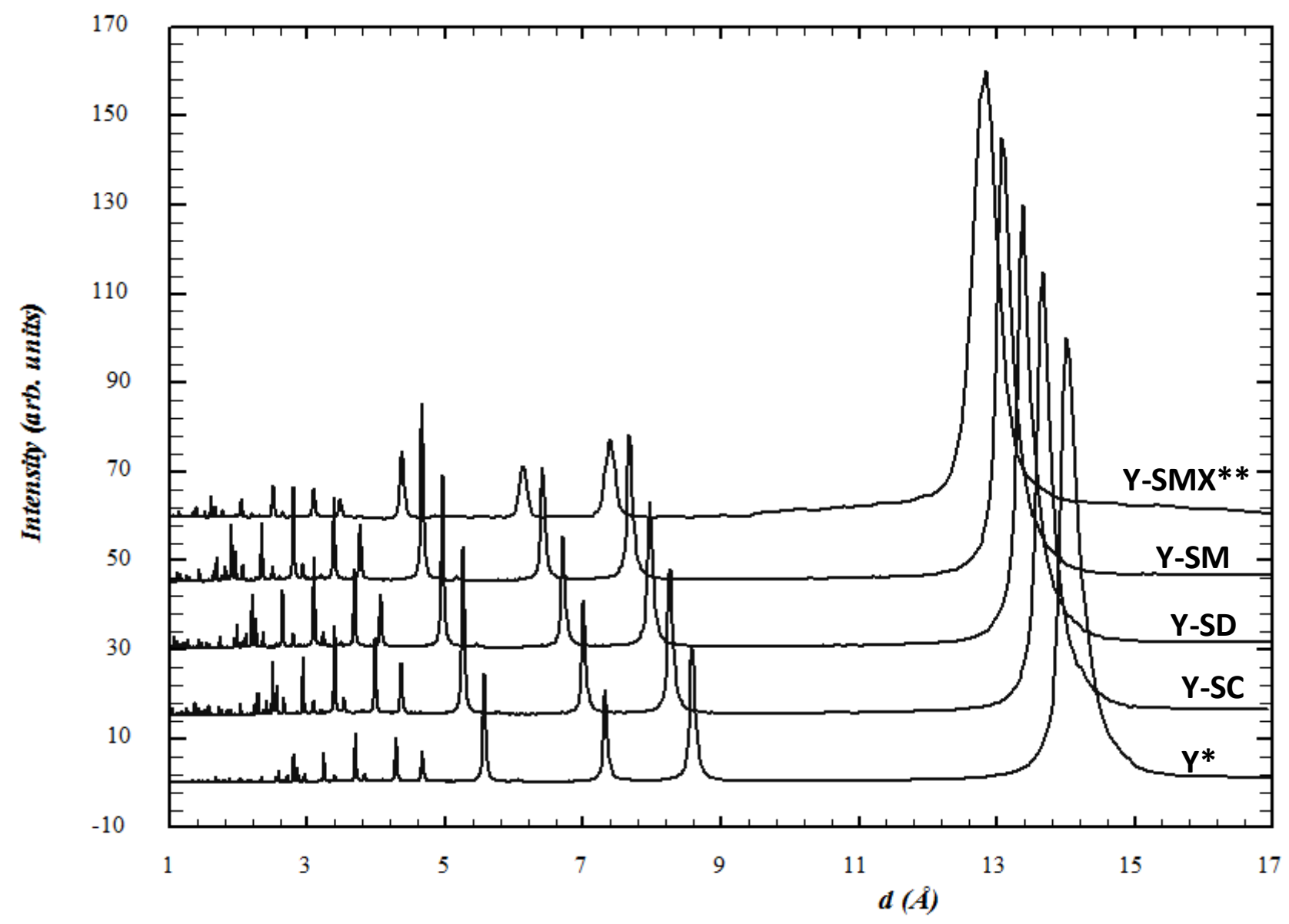

Figure 4. 

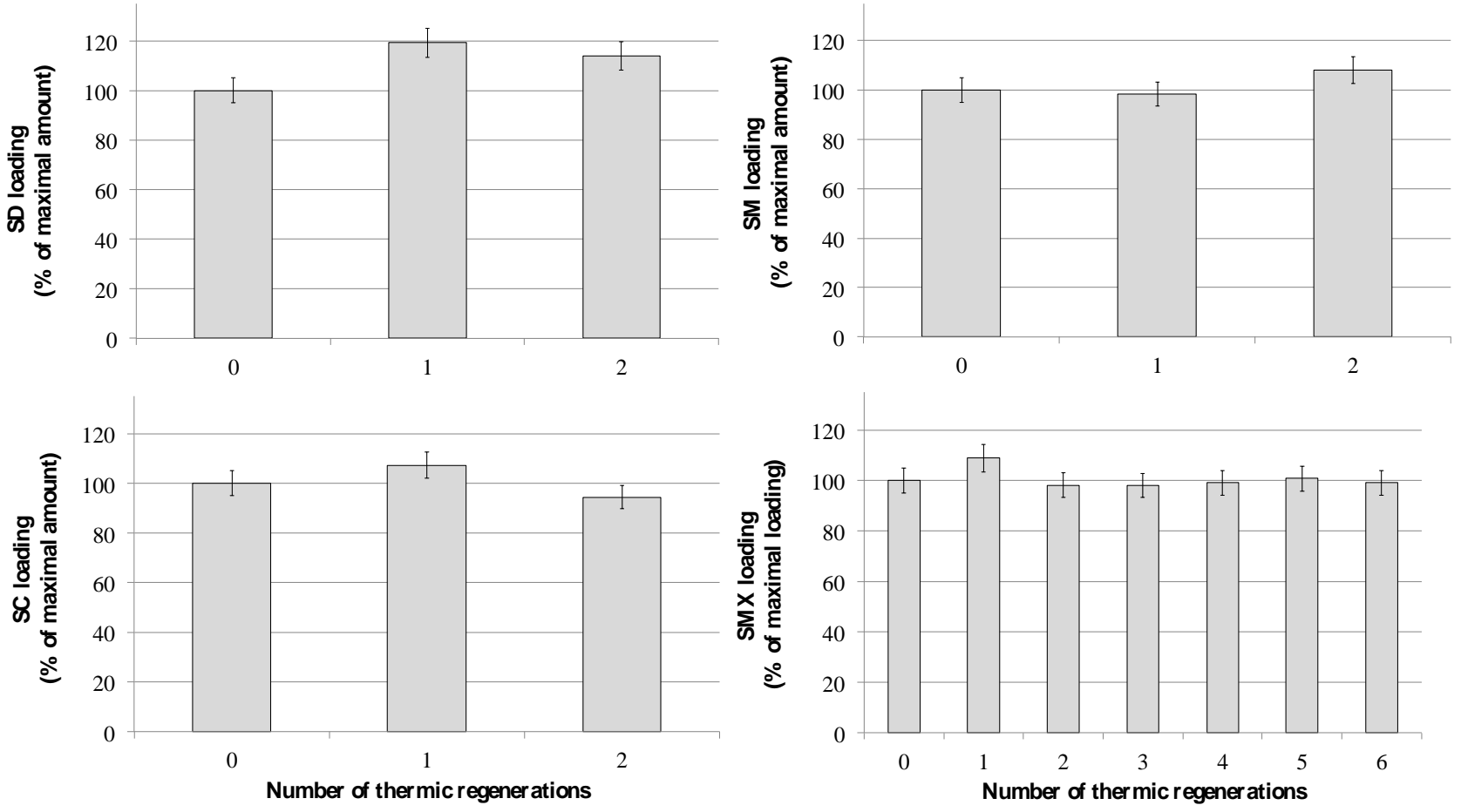

Figure 5. 

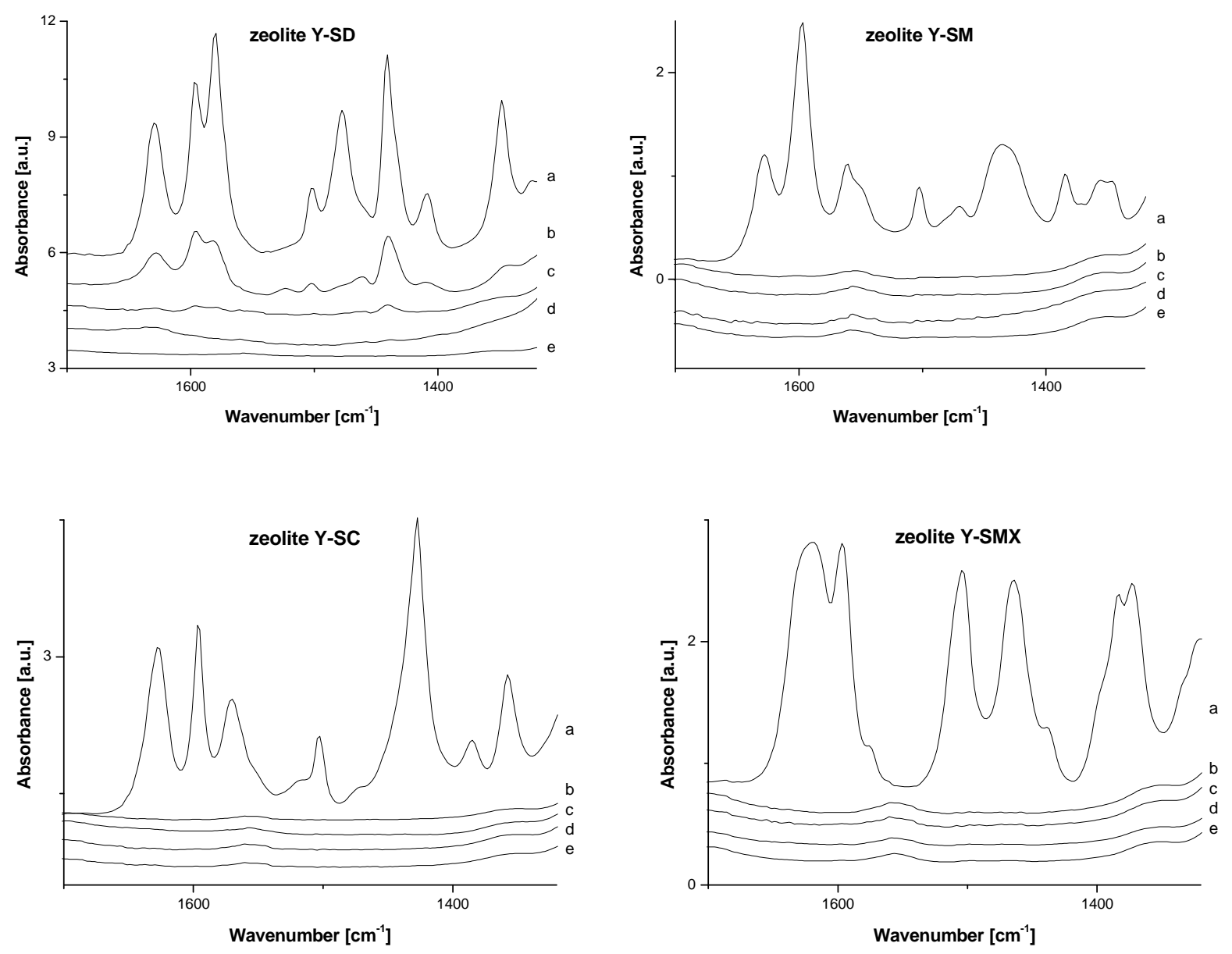

Figure 6. 